\title{
CONCENTRAÇÃO ESPACIAL DOS REBANHOS DE SUÍNOS NO BRASIL ENTRE 1990 E $2012^{1}$
}

\section{SWINE CATTLE SPATIAL CONCENTRATION AT BRASIL BETWEEN 1990 AND 2012}

\author{
Laércio Juarez Melz ${ }^{2}$ \\ Tiane Alves Rocha Gastardelo ${ }^{3}$ \\ Pascoal José Marion Filho ${ }^{4}$
}

\begin{abstract}
Resumo
A concentração de mercado pode ser entendida como uma forma de avaliar o aumento de poder de mercado por parte das firmas. O objetivo deste artigo foi verificar se houve redução ou aumento da concentração espacial da produção de suínos no Brasil no contexto dos estados e das microrregiões. O período de análise foi entre os anos de 1990 e 2012 com dados de rebanho dos 26 estados brasileiros e de 294 microrregiões pertencentes aos oito maiores estados produtores de suínos. Adaptando-se os índices de Razão de Concentração (CR) e Herfindahl-Hirschman (HHI) para medir o aumento da concentração dos rebanhos em determinados estados e microrregiões, pode-se identificar tendências de concentração regional. Verificou-se que houve aumento da concentração nos estados da região Sul e Centro-Oeste, principalmente. Também dentro destes estados os a produção de suínos tem se concentrado em poucas microrregiões. Justifica-se a concentração nas microrregiões, a partir da teoria, devido à sua grande disponibilidade de milho.

Palavras-chave: Estruturas de mercado. Razão de concentração (CR). Índice de HerfindahlHirschman (HHI).
\end{abstract}

\begin{abstract}
The market concentration can be understood as a way to assess the increase of market power by firms. The purpose of this article was to examine if there was decreased or increased spatial concentration of swine production in Brazil in the context of states and micro-regions. The analysis period was between 1990 and 2012 with livestock data collected from 26 Brazilian states and 294 micro-regions belonging to eight major swine producing states. Adapting the contents of Concentration Ratio (CR) and Herfindahl-Hirschman Index (HHI) to measure the concentration of livestock in certain states and micro, it was possible identify trends of regional concentration. It was found that there was increased concentration in the states of the South and Midwest, mostly. Also within these states the swine production has been concentrated in a few micro-regions. The concentration in the regions is justified, by theory, due to its wide availability of corn.
\end{abstract}

Keywords: Market structures. Concentration Ratio (CR). Herfindahl-Hirschman Index (HHI).

\footnotetext{
${ }^{1}$ Artigo apresentado parcialmente no $52^{\circ}$ Congresso da Sober, em Goiânia-GO.

2 Doutorando em Administração (UFSM), Mestre em Engenharia de Produção (UFSCar), Professor de Contabilidade da Universidade do Estado de Mato Grosso (UNEMAT), Bolsista FAPEMAT. laercio@unemat.br

${ }^{3}$ Mestranda em Administração (UFSM). tianealvesrocha@ gmail.com

${ }^{4}$ Doutor em Economia Aplicada (ESALQ), Professor de Economia da Universidade Federal de Santa Maria (UFSM). E-mail: 


\section{INTRODUÇÃO}

Na década de 80 houve aumento do grau de concentração entre as quatro maiores empresas processadoras, sendo que $48 \%$ pertencentes à quatro grupos catarinenses (WEYDMANN, 2004). Segundo Resende e Boff (2002) medidas de concentração são úteis como indicadores preliminares de significativo poder de mercado. Assim, quanto maior é a concentração em poucas empresas, maior é o poder de definição de preços no mercado. Rhoades (1985) aponta algumas evidencias de associação entre concentração e poder de mercado. Maior poder de mercado reduz a competitividade das empresas e aumenta a possibilidade de imposição de barreiras à entrada, principalmente relacionadas aos ganhos em economias de escala.

Em termos regionais, estabelecer unidades de abate, no caso dos suínos, próximas aos produtores é necessário. Isso porque o transporte dos animais para longas distâncias aumenta as taxas de mortalidade, causando perdas econômicas (SANTOS, REIS, et al., 2013). Melz, Gasparini e Souza Filho (2009) verificaram o movimento da produção de frangos em direção à região Centro-Oeste. Os autores alegaram que o principal motivo foi a proximidade com os insumos, milho e soja, abundantes nesta região. Os mesmos insumos representam $70 \%$ dos custos de produção dos suínos, assim, o mesmo movimento pode ser esperado ( IPARDES; IBQP; GEPAI, 2002). Weydemann (2004) também apontou um crescimento do rebanho no Centro-Oeste. Isso pode ser parte de uma estratégia das firmas de abate e processamento para reduzir custos de transação locacionais, aproximando as plantas e, consequentemente os rebanhos, dos principais centros produtores de insumos.

O objetivo deste artigo é verificar se houve redução ou aumento da concentração espacial da produção de suínos no Brasil no contexto dos estados e das microrregiões. Como objetivo secundário, pretende-se apresentar as mudanças entre os principais locais de produção entre os anos de 1990 e 2012.

\section{ORIGEM DA SUINOCULTURA NO MUNDO}

O consumo de carne faz parte das necessidades básicas do ser humano. O desenvolvimento das civilizações ocidentais está intimamente ligado ao consumo de produtos 
Concentração espacial dos rebanhos de suínos no Brasil entre 1990 e 2012

Laércio Juarez Melz

Tiane Alves Rocha Gastardelo

Pascoal José Marion Filho

de origem animal. Inicialmente o ser humano subsistia da caça e migrava de tempos em tempos à procura de novos locais para a prática. Os suínos e outros animais eram transportados vivos para abate durante grandes viagens, pois, não havia tecnologia para conservação da carne. Contribuíram para sua domesticação a sua natureza onívora, que facilitou a alimentação dos animais, o seu tamanho e seu curto ciclo produtivo. A partir da domesticação dos animais o ser humano pode fixar-se em uma região, gerando o modo de vida predominante até a atualidade.

A origem dos suínos domesticados não é muito clara, pois, ainda não foram encontradas evidências científicas suficientes precisar sua origem. Contudo, existem indícios arqueológicos sobre a domesticação dos animais entre 13.000 e 12.700 A.C. no Oriente Médio, bacia do Rio Tigre ( NELSON, 1998). Restos de suínos foram datados de antes de 11.400 A.C., no Chipre, que deve ter sido introduzida a partir de continentes próximos, o que sugere a domesticação no continente de origem até então ( VIGNE, et al., 2009).

Giuffra et al. (2000) verificaram que a domesticação ocorreu de forma simultânea na Europa e na China cerca de 9000 atrás. Larson et al. (2007) afirmam que a domesticação na Europa ocorreu a partir de 4000 A.C., período Neolítico, com a introdução de espécies vindas do Oriente Médio, principalmente para a Itália e, em seguida, a região norte da Alemanha e de Paris, na França, e mais tarde para Portugal, Suiça, República Checa, Croácia e Romênia.

$\mathrm{Na}$ América, mais especificamente em Cuba, os suínos foram introduzidos por Cristóvão Colombo em 1493, porém foi Hernando de Soto quem trouxe 13 animais para a baía de Tampa, na Flórida, em 1539, Hernando Cortez no Novo México, em 1600, e Sr. Walter Raleigh na Colônia de Jamestown, em 1607, difundindo a suinocultura no continente. Nos Estados Unidos a expansão da suinocultura acompanhou a produção de milho, no chamado corn belt a partir de 1660. Entre 1800 e 1900 a construção e ampliação das ferrovias 
Concentração espacial dos rebanhos de suínos no Brasil entre 1990 e 2012

Laércio Juarez Melz

Tiane Alves Rocha Gastardelo

Pascoal José Marion Filho

no país, aliada à introdução de vagões refrigerados facilitou a expansão da produção por todo aquele país ( NATIONAL PORK BOARD, 2014).

\section{MARCO TEÓRICO E METODOLÓGICO}

Os índices CR, normalmente, referem-se à concentração da participação das empresas em um mercado. Através da razão de concentração é possível verificar quantas empresas dominam o mercado de um dado produto. Cada empresa possui uma participação no mercado, representada divisão de suas vendas pelas vendas totais do mercado. Ordenando-se as empresas, da maior participação para a menor participação, e somando-se as participações das $k$ maiores empresas é possível verificar qual a parcela de mercado pertence às $4,8,10,12 \ldots n$ maiores participantes.

$\mathrm{Na}$ formulação do índice, $k$ representa o limite superior de empresas que terão sua participação somada. Neste caso, se $k=4$, seriam somadas as participações das 4 maiores empresas do mercado, se $k=8$, seriam as oito maiores. É mais comum utilizar-se para as quatro, oito e dezesseis maiores empresas (MARQUES, 1994), todavia, pode-se utilizar outras variações, dependendo do interesse da pesquisa. A função matemática que permite o cálculo da razão de concentração das $k$ maiores empresas do mercado é mostrada na Equação (1).

onde:

$$
C R(k)=\sum_{i=1}^{k} S_{i}
$$

$k$ é o número de produtores;

$S$ é a receita dos $k$ maiores produtores.

Resende e Boff (2002) tecem algumas críticas ao índice CR, principalmente por não existir individualização das $k$ maiores e, assim, não é possível identificar aumentos na concentração quando empresas que estão neste grupo se fundem. Mesmo entre empresas que não pertencem ao grupo das $k$ maiores podem ocorrer fusões horizontais que afetam a concentração do mercado, mas não são detectadas pelo referido índice. 
Aos índices de concentração foram atribuídas classificações de acordo com os percentuais de participação dos quatro e oito maiores agentes do mercado, adaptados de Medeiros e Ostroski (2006), demonstrados no quadro 1.

\begin{tabular}{|l|c|c|}
\hline \multicolumn{1}{|c|}{ Níveis de mercado } & \multicolumn{2}{c|}{ Razão de Concentração } \\
& CR4 & CR8 \\
Altamente concentrado & $\mathrm{i}>75 \%$ & $\mathrm{i}>90 \%$ \\
Alta concentração & $65 \%<\mathrm{i}<75 \%$ & $70 \%<\mathrm{i}<90 \%$ \\
Concentração moderada & $50 \%<\mathrm{i}<65 \%$ & $45 \%<\mathrm{i}<70 \%$ \\
Baixa concentração & $35 \%<\mathrm{i}<50 \%$ & $\mathrm{i}<45 \%$ \\
Ausência de concentração & $\mathrm{i}<35 \%$ & \\
Claramente atomístico & $=2 \%$ & \\
\hline
\end{tabular}

Quadro 1. Tipos de mercado segundo a razão de concentração (CR).

Fonte: Medeiros e Ostroski (2006).

Para superar as limitações dos índices existentes foi desenvolvido o índice de Herfindahl-Hirschman. A diferença entre o índice de Herfindahl-Hirschman e a razão de concentração, em se tratando da fórmula, é que a somatória dos percentuais de participação deve ser elevada ao quadrado, dando, assim, maior peso aos maiores participantes. Quanto maior o valor do índice, maior será o nível de concentração do mercado (RESENDE; BOFF, 2002). O índice pode ser calculado através da fórmula do quadro 2 e o intervalo de valores pode ir de 0 a 10.000 , quando calculado com percentuais, ou de 0 a 1 , quando se utilizam números índices.

$$
H H I=\sum_{i=1}^{n} S_{i}^{2}
$$

onde:

$n$ é o número total de firmas de uma indústria.

$S$ é a receita de cada firma;

O limite superior, 10.000 ou 1, está sempre associado ao grau máximo de concentração de um mercado, o monopólio (RESENDE; BOFF, 2002). O Departamento de Justiça Americano e a Comissão Federal de Comércio dos Estados Unidos apontam três níveis de concentração baseados no Índice de Herfindahl-Hirschman, como forma de aprovar ou reprovar fusões horizontais de empresas ( USDJ; FTC, 2010). Assim o índice é calculado a partir do cenário pós fusão e classificado entre 0 e 1500, como não concentrado, entre 1500 e 2500 como moderadamente concentrado e acima de 2500 é considerado altamente 
Concentração espacial dos rebanhos de suínos no Brasil entre 1990 e 2012

Laércio Juarez Melz

Tiane Alves Rocha Gastardelo

Pascoal José Marion Filho

concentrado. $\mathrm{O}$ índice HH possui limitações quando não é possível identificar as participações de todas as empresas no mercado. Neste caso uma opção que pode ser viável é a utilização da razão de concentração CR4, CR8 ou CR16, de acordo com os dados disponíveis.

\subsection{Fonte dos dados}

O Instituto Brasileiro de Geografia e Estatística (IBGE) mantém um banco de dados que contém os estoques dos produtos de origem animal no Brasil, incluindo os rebanhos. $\mathrm{O}$ banco de dados é atualizado anualmente a partir da Pesquisa Pecuária Municipal (PPM). As séries anuais do rebanho suíno entre 1990 e 2012 foram coletadas neste banco de dados em três tabelas.

Primeiro foram coletados os dados dos rebanhos dos 26 estados, sendo selecionados os oito maiores players para o detalhamento em microrregiões. Em seguida das 294 microrregiões destes 8 estados.

Em cada tabela de dados foram classificados os maiores produtores, aplicando-se as equações (1) e (2) para obter os índices CR4, CR8 e HHI. A classificação também foi utilizada para conhecer quais os maiores produtores em cada ano analisado, para verificar as mudanças na sua composição.

\section{RESULTADOS}

Os resultados são apresentados em três seções. Na primeira são apresentados os índices de concentração dos estados em relação ao Brasil, bem como a sua evolução em termos de quantidades de animais alojados. Na segunda seção os índices de concentração e sua evolução nas microrregiões pertencentes aos oito estados brasileiros com maiores participações em 2012, demonstrados na primeira seção. Na terceria seção são tecidos alguns comentários sobre os níveis de concentração nas microrregiões em relação aos estados ao longo do tempo, bem como alguns motivadores para esta evolução.

\subsection{Concentração entre os estados}

A Tabela 1 mostra a evolução dos índices de concentração (CR4, CR8, HHI) além dos estados componentes do grupo dos oito maiores e o rebanho total de suínos do Brasil entre 
Concentração espacial dos rebanhos de suínos no Brasil entre 1990 e 2012

Laércio Juarez Melz

Tiane Alves Rocha Gastardelo

Pascoal José Marion Filho

1990 e 2012. Nota-se que, a partir de 1995, houve um salto no nível de concentração entre os quatro maiores estados produtores de suínos. Esse aumento está relacionado com o aumento dos rebanhos em Santa Catarina em Minas Gerais.

A composição dos quatro maiores estados produtores manteve-se a mesma no período analisado. Os quatro maiores foram Santa Catarina, Rio Grande do Sul, Paraná e Minas Gerais. Outro ponto que deve ser destacado é que o nível de concentração, de acordo com a classificação de Medeiros e Ostroski (2006), passou de baixa concentração até 1995 para um nível de concentração moderada. Este nível vem aproximando-se dos $65 \%$, quando passa a ser de alta concentração, segundo os autores.

Entre os oito maiores (CR8), percebe-se que há troca de posições entre Maranhão e Bahia, que perderam espaço para os estados de São Paulo, Goiás e Mato Grosso. Goiás começou a destacar-se em 2003 e Mato Grosso apenas em 2008. O nível de concentração entre os oito maiores também tem aumentado, sendo que em 1993 passou a ser de concentração moderada, aproximando-se da alta concentração em 2012.

Tabela 1 - Razão de Concentração, Índice de Herfindahl-Hirschman, principais estados produtores e rebanho nacional de suínos entre 1990 e 2012

\begin{tabular}{|c|c|c|c|c|c|c|c|c|c|c|c|c|}
\hline Ano & CR4 & CR8 & HHI & UF 1 & UF 2 & UF 3 & UF 4 & UF 5 & UF 6 & UF 7 & UF 8 & Rebanho BR \\
\hline 1990 & $41 \%$ & $9 \%$ & 731 & $\mathrm{RS}$ & PR & SC & MG & MA & BA & SP & PA & 33.623 .186 \\
\hline 91 & $\%$ & $\%$ & 722 & RS & PR & MG & $\mathrm{SC}$ & MA & BA & SP & PA & .275 \\
\hline 92 & $\%$ & $\%$ & 728 & & PR & $\overline{C r}$ & MG & & A & SP & & \\
\hline 93 & $\%$ & $\%$ & 752 & & $\mathrm{PR}$ & $\overline{\mathrm{C}}$ & $G$ & t & $\bar{A}$ & $\mathrm{PA}$ & SP & \\
\hline 994 & $\%$ & $\%$ & 752 & $\mathrm{RS}$ & $\mathrm{SC}$ & $\mathrm{R}$ & IG & MA & $\mathrm{BA}$ & SP & PA & \\
\hline 1995 & $\%$ & $0 \%$ & 756 & SC & $\mathrm{RS}$ & PR & MG & MA & $\mathrm{BA}$ & SP & PA & 103 \\
\hline 1996 & $\%$ & $5 \%$ & 898 & SC & PR & $\mathrm{RS}$ & MG & MA & SP & BA & PI & \\
\hline 1997 & $2 \%$ & $\%$ & 898 & SC & $\mathrm{PR}$ & $\mathrm{RS}$ & IG & MA & SP & BA & PI & 109 \\
\hline 1998 & $\%$ & $6 \%$ & 904 & SC & $P R$ & $R_{s}^{s}$ & $\mathrm{G}$ & SP & MA & $\mathrm{BA}$ & PI & \\
\hline 1999 & $\%$ & $5 \%$ & 903 & $\mathrm{SC}$ & $\overline{\mathrm{PR}}$ & RS & G & $\overline{\mathrm{BA}}$ & $\overline{\mathrm{SP}}$ & MA & 1 & \\
\hline 000 & $\%$ & $\%$ & 904 & $\mathrm{SC}$ & $\mathrm{PR}$ & KS & MG & BA & SP & MA & 1 & \\
\hline 001 & $\%$ & $5 \%$ & 915 & SC & PR & RS & IG & A & SP & पA & PI & 112 \\
\hline 2002 & $\%$ & $\%$ & 914 & $\overline{\mathrm{SC}}$ & PR & KS & $\overline{\mathrm{IG}}$ & BA & SP & MA & PI & 749 \\
\hline 2003 & $4 \%$ & $5 \%$ & 920 & $\mathrm{SC}$ & $\mathrm{PR}$ & $\mathrm{RS}$ & MG & BA & MA & SP & GO & 905 \\
\hline 2004 & $\%$ & $5 \%$ & 938 & SC & PR & $\mathrm{RS}$ & $\mathrm{G}$ & $\mathrm{BA}$ & SP & MA & $\mathrm{GO}$ & \\
\hline 2005 & $\%$ & $5 \%$ & 96 & $\mathrm{SC}$ & $\overline{\mathrm{PR}}$ & K & & BA & SP & IA & GO & \\
\hline 006 & $\%$ & $5 \%$ & 08 & $\mathrm{SC}$ & PR & $R S$ & MG & $3 \mathrm{~A}$ & SP & AA & $\mathrm{O}$ & \\
\hline 2007 & $\%$ & $3 \%$ & 54 & SC & $\mathrm{RS}$ & PR & IG & A & SP & GO & MA & 15 \\
\hline 2008 & $60 \%$ & $78 \%$ & 93 & SC & $\mathrm{RS}$ & $\mathrm{PR}$ & IG & $\mathrm{BA}$ & SP & MT & GO & 017 \\
\hline 2009 & $\%$ & $0 \%$ & 01 & $\mathrm{SC}$ & $\mathrm{RS}$ & PR & MG & GO & MT & BA & SP & 454 \\
\hline 2010 & $61 \%$ & $80 \%$ & 1.093 & $\mathrm{SC}$ & $\mathrm{RS}$ & PR & MG & MT & $\mathrm{GO}$ & BA & SP & 758 \\
\hline 2011 & $1 \%$ & $80 \%$ & 1.104 & $\mathrm{SC}$ & $\mathrm{RS}$ & $\mathrm{PR}$ & 101 & $\mathrm{GC}$ & MT & BA & SP & \\
\hline 2012 & $3 \%$ & $1 \%$ & 129 & SC & $\mathrm{RS}$ & $P R$ & MG & $\mathrm{GC}$ & MT & $\overline{\mathrm{SP}}$ & $\mathrm{BA}$ & 38.795 .902 \\
\hline
\end{tabular}

Fonte : Elaborado pelos autores com dados do IBGE (2014). 
Concentração espacial dos rebanhos de suínos no Brasil entre 1990 e 2012 Laércio Juarez Melz

Tiane Alves Rocha Gastardelo

Pascoal José Marion Filho

O índice de Herfindahl-Hirschman, cujo limite superior é 10.000, não corrobora o alto nível de concentração, sendo classificado como baixa concentração pelos critérios adotados pelo USDJ e FTC (2010). Contudo, confirma o aumento do nível de concentração dos rebanhos no Brasil.

Outra constatação é que, entre 1996 e 2004, houve uma retração na produção de suínos em quase todos os estados, exceto Paraná, Santa Catarina e Mato Grosso do Sul, que mantiveram aumentos regulares nos seus rebanhos. Os estados de Santa Catarina, Rio Grande do Sul, Paraná, Minas Gerais, Goiás, Mato Grosso, São Paulo e Bahia têm permanecido no grupo dos oito maiores desde 2008. Nestes últimos cinco anos os estados do Sul e Minas gerais vem consolidando-se como os principais produtores de suínos.

\subsection{Concentração entre as microrregiões dos principais estados brasileiros}

Em Santa Catarina o nível de concentração tem aumentado entre 1990 e 2012, contudo, com o CR4 premanecendo no nível de concentração moderada até 1998, pela classificação de Medeiros e Ostroski (2006). Entre os anos 1999 e 2011, a concentração (CR4) foi alta, principalmente pelo aumento da produção das microrregiões de Concórdia e Joaçaba. Concórdia desde o início da série detinha o maior rebanho de suínos de Santa Catarina e Joaçaba já era uma das quatro maiores e vem aumentando sua participação, principalmente a partir de 1997 (Tabela 2).

Tabela 2 - Razão de Concentração, Herfindahl-Hirschman, total de rebanhos e principais microrregiões produtoras de suínos de Santa Catarina, 1990-2012.

\begin{tabular}{c|c|c|c|c|c|c|c|c|c}
\hline Ano & CR4 & CR8 & HHI & Total & Ano & CR4 & CR8 & HHI & Total \\
\hline 1990 & $60 \%$ & $82 \%$ & 1.068 & 3.330 .516 & 2002 & $67 \%$ & $91 \%$ & 1.439 & 5.354 .113 \\
\hline 1991 & $60 \%$ & $82 \%$ & 1.069 & 3.275 .024 & 2003 & $68 \%$ & $91 \%$ & 1.454 & 5.432 .143 \\
\hline 1992 & $58 \%$ & $83 \%$ & 1.060 & 3.417 .586 & 2004 & $69 \%$ & $92 \%$ & 1.493 & 5.775 .890 \\
\hline 1993 & $60 \%$ & $84 \%$ & 1.121 & 3.727 .711 & 2005 & $68 \%$ & $92 \%$ & 1.448 & 6.309 .041 \\
\hline 1994 & $60 \%$ & $84 \%$ & 1.116 & 4.088 .621 & 2006 & $68 \%$ & $93 \%$ & 1.578 & 7.158 .596 \\
\hline 1995 & $61 \%$ & $85 \%$ & 1.155 & 4.404 .480 & 2007 & $67 \%$ & $93 \%$ & 1.496 & 7.156 .013 \\
\hline 1996 & $65 \%$ & $89 \%$ & 1.308 & 4.532 .654 & 2008 & $66 \%$ & $93 \%$ & 1.490 & 7.846 .398 \\
\hline 1997 & $65 \%$ & $89 \%$ & 1.310 & 4.558 .963 & 2009 & $67 \%$ & $93 \%$ & 1.483 & 7.988 .663 \\
\hline 1998 & $65 \%$ & $89 \%$ & 1.335 & 4.704 .545 & 2010 & $67 \%$ & $93 \%$ & 1.462 & 7.817 .536 \\
\hline 1999 & $66 \%$ & $89 \%$ & 1.384 & 4.814 .297 & 2011 & $66 \%$ & $93 \%$ & 1.419 & 7.968 .116 \\
\hline 2000 & $66 \%$ & $90 \%$ & 1.388 & 5.093 .888 & 2012 & $65 \%$ & $93 \%$ & 1.392 & 7.480 .183 \\
\hline 2001 & $67 \%$ & $91 \%$ & 1.411 & 5.516 .818 & & & & & \\
\hline
\end{tabular}

Fonte : Elaborado pelos autores com dados do IBGE (2014).

Entre os oito maiores (CR8) o nível de concentração passou a ser considerado alto a partir do ano de 1995 até 1999, passando a ser altamente concentrado desde 2000, com mais 
Concentração espacial dos rebanhos de suínos no Brasil entre 1990 e 2012 Laércio Juarez Melz

Tiane Alves Rocha Gastardelo

Pascoal José Marion Filho

de $90 \%$ de concentração. O índice de Herfindahl-Hirschman confirma essa tendência de crescimento, sendo os valores considerados de ausência de concentração pelos critérios adotados pelo USDJ e FTC (2010), exceto pelo ano de 2006, com valor pouco maior que 1500.

A Figura 1 mostra a evolução dos rebanhos em número de cabeças nas microrregiões de Santa Catarina. Percebe-se que todas aumentaram seus rebanhos desde o início da série. A microrregião de Concórdia teve um salto em seus rebanhos em 2006, contudo não manteve este nível após 2009. Joaçaba tem mantido crescimentos regulares nos rebanhos podendo, inclusive, ultrapassar Concórdia nos próximos anos.

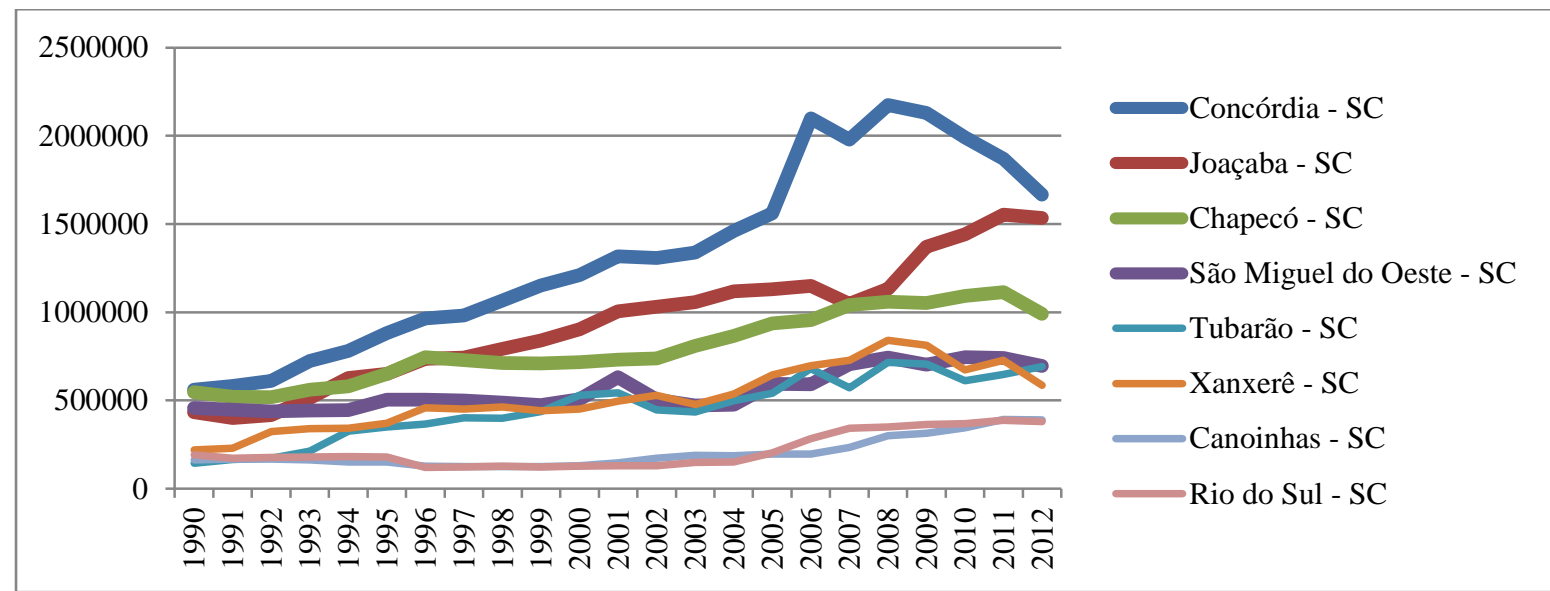

Figura 1 - Rebanho de suínos nas microrregiões de Santa Catarina, em cabeças, 1990-2012

Fonte : Elaborado pelos autores com dados do IBGE (2014).

A Figura 1 também mostra que existe grande diferença de rebanhos entre as três principais microrregiões e as demais. Esse distanciamento pode consolidar a concentração regional da produção, sendo o oeste de Santa Catarina o local com mais microrregiões produtoras.

No Rio Grande do sul, até 2001, o índice CR4 apontava ausência de concentração. Após esse ano, a concentração passou a ser baixa entre as quatro maiores microrregiões produtoras. Entre os oito maiores o nível entre $45 \%$ e $70 \%$ é de baixa concentração da produção.

Tabela 3 - Razão de Concentração, Herfindahl-Hirschman, total de rebanhos de suínos do Rio Grande do Sul, 19902012

\begin{tabular}{c|c|c|c|c|c|c|c|c|c}
\hline Ano & CR4 & CR8 & HHI & Total & Ano & CR4 & CR8 & HHI & Total \\
\hline 1990 & $30 \%$ & $49 \%$ & 442 & 3.744 .687 & 2002 & $35 \%$ & $57 \%$ & 534 & 4.036 .952 \\
\hline 1991 & $30 \%$ & $49 \%$ & 444 & 3.854 .184 & 2003 & $38 \%$ & $59 \%$ & 579 & 4.145 .052 \\
\hline 1992 & $30 \%$ & $49 \%$ & 445 & 3.929 .082 & 2004 & $38 \%$ & $60 \%$ & 582 & 4.094 .030 \\
\hline
\end{tabular}


Concentração espacial dos rebanhos de suínos no Brasil entre 1990 e 2012

Laércio Juarez Melz

Tiane Alves Rocha Gastardelo

Pascoal José Marion Filho

\begin{tabular}{l|l|l|l|l|l|l|l|l|l}
\hline 1993 & $31 \%$ & $51 \%$ & 466 & 4.043 .449 & 2005 & $38 \%$ & $60 \%$ & 595 & 4.233 .791 \\
\hline 1994 & $31 \%$ & $50 \%$ & 460 & 4.181 .965 & 2006 & $39 \%$ & $62 \%$ & 609 & 4.339 .484 \\
\hline 1995 & $30 \%$ & $51 \%$ & 454 & 4.245 .566 & 2007 & $40 \%$ & $61 \%$ & 636 & 5.197 .008 \\
\hline 1996 & $31 \%$ & $52 \%$ & 476 & 3.922 .591 & 2008 & $38 \%$ & $61 \%$ & 601 & 5.320 .252 \\
\hline 1997 & $31 \%$ & $52 \%$ & 480 & 4.066 .847 & 2009 & $39 \%$ & $61 \%$ & 612 & 5.344 .318 \\
\hline 1998 & $31 \%$ & $52 \%$ & 479 & 4.055 .024 & 2010 & $41 \%$ & $63 \%$ & 665 & 5.729 .710 \\
\hline 1999 & $31 \%$ & $53 \%$ & 483 & 4.140 .468 & 2011 & $42 \%$ & $64 \%$ & 670 & 5.677 .515 \\
\hline 2000 & $32 \%$ & $54 \%$ & 491 & 4.133 .303 & 2012 & $41 \%$ & $67 \%$ & 675 & 6.213 .316 \\
\hline 2001 & $34 \%$ & $55 \%$ & 510 & 4.076 .247 & & & & & \\
\hline
\end{tabular}

Fonte : Elaborado pelos autores com dados do IBGE (2014).

Observa-se o aumento paulatino da concentração entre as microrregiões ao longo do tempo. Diferente de Santa Catarina e Paraná, onde há distancimento da quantidade de animais em estoque a partir da quarta região mais representativa, no Rio Grande do Sul, os estoques seguem com aproximadamente o mesmo número de animais, exceto pela microrregião de Lajeado-Estrela, que tem se distanciado das demais desde 2010 (Figura 2).

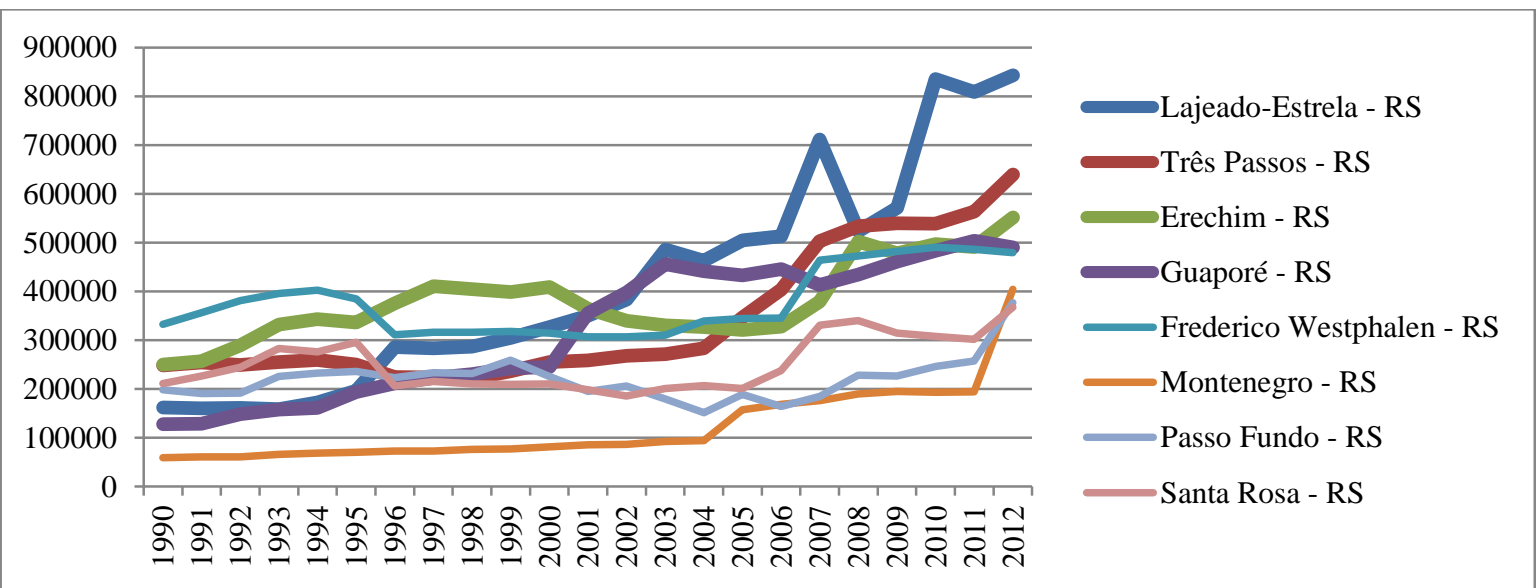

Figura 2 - Rebanho de suínos nas microrregiões do Rio Grande do Sul, em cabeças, 1990-2012 Fonte : Elaborado pelos autores com dados do IBGE (2014).

No Paraná, assim como os demais estados da região Sul os níveis de concentração vem aumentando. Isso confirma-se em ambos os índices. Em 1990, o índice de concentração dos quatro maiores (CR4), apontava baixa concentração. Em 2009 o nível de concentração (CR4) passou a ser moderado. O CR8, aponta aumento da concentração apenas a partir de 2011. O índice de Herfindahl-Hirschman passou a aumentar de forma mais acentuada a partir de 2004, motivado pelo aumento dos rebanhos na microrregião de Toledo (Tabela 4). Contudo, o HHI ainda demonstra ausência de concentração.

Tabela 4 - Razão de Concentração, Herfindahl-Hirschman, total de rebanhos de suínos do Paraná, 1990-2012

\begin{tabular}{l|l|l|r|l|l|l|l|l|l}
\hline Ano & CR4 & CR8 & HHI & Total & Ano & CR4 & CR8 & HHI & Total \\
\hline 1990 & $36 \%$ & $53 \%$ & 539 & 3561765 & 2002 & $41 \%$ & $59 \%$ & 703,29 & 4258075 \\
\hline
\end{tabular}


Concentração espacial dos rebanhos de suínos no Brasil entre 1990 e 2012

Laércio Juarez Melz

Tiane Alves Rocha Gastardelo

Pascoal José Marion Filho

\begin{tabular}{l|l|l|l|l|l|l|l|l|l}
\hline 1991 & $36 \%$ & $52 \%$ & 566 & 3698205 & 2003 & $40 \%$ & $59 \%$ & 667,72 & 4364371 \\
\hline 1992 & $37 \%$ & $54 \%$ & 572 & 3738365 & 2004 & $44 \%$ & $62 \%$ & 751,15 & 4588053 \\
\hline 1993 & $37 \%$ & $53 \%$ & 574 & 3780172 & 2005 & $44 \%$ & $63 \%$ & 766,97 & 4547895 \\
\hline 1994 & $39 \%$ & $54 \%$ & 623 & 3762598 & 2006 & $44 \%$ & $63 \%$ & 784,58 & 4486035 \\
\hline 1995 & $40 \%$ & $55 \%$ & 645 & 3929536 & 2007 & $45 \%$ & $65 \%$ & 859,99 & 4735956 \\
\hline 1996 & $39 \%$ & $60 \%$ & 637 & 4065636 & 2008 & $47 \%$ & $66 \%$ & 939,56 & 4631600 \\
\hline 1997 & $39 \%$ & $59 \%$ & 620 & 4121617 & 2009 & $50 \%$ & $68 \%$ & 949,68 & 5105005 \\
\hline 1998 & $40 \%$ & $59 \%$ & 649 & 4187113 & 2010 & $51 \%$ & $69 \%$ & 973,68 & 5096224 \\
\hline 1999 & $41 \%$ & $58 \%$ & 666 & 4217063 & 2011 & $53 \%$ & $72 \%$ & 1124,8 & 5448964 \\
\hline 2000 & $41 \%$ & $58 \%$ & 660 & 4224838 & 2012 & $57 \%$ & $74 \%$ & 1230,3 & 5518927 \\
\hline 2001 & $42 \%$ & $59 \%$ & 692 & 4385914 & & & & & \\
\hline
\end{tabular}

Fonte : Elaborado pelos autores com dados do IBGE (2014).

A microrregião de Toledo é destaque, pois, tem aumentado seu rebanho de suínos e distanciado-se das demais ao longo dos anos. Seu estoque em 2012 foi quase três vezes maior que o da segunda microrregião e representava $29 \%$ do total do estado. As demais microrregiões do Paraná mantiveram o mesmo nível de rebanhos ao longo da série (Figura 3).

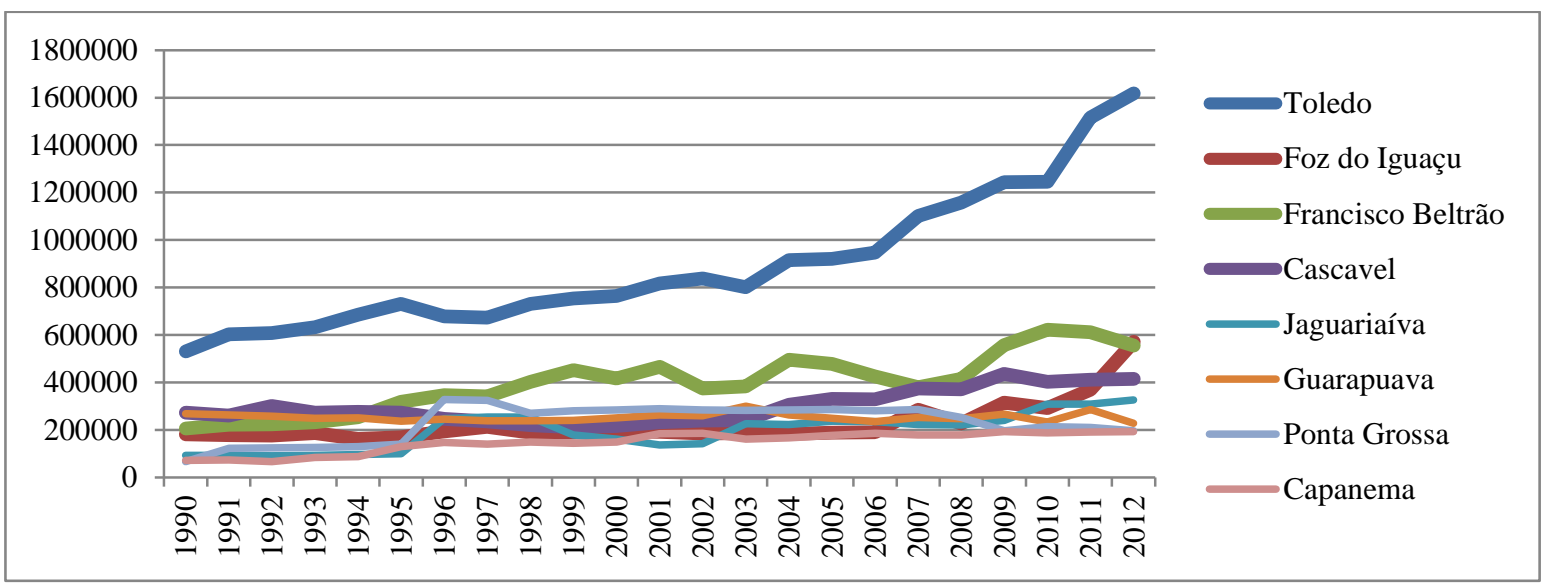

Figura 3 - Rebanho de suínos nas microrregiões do Paraná, em cabeças, 1990-2012 Fonte : Elaborado pelos autores com dados do IBGE (2014).

Em Minas Gerais os índices apontam ausência de concentração entre as quatro microrregiões com maiores rebanhos até 1998. Em 1999 a concentração passou a ser baixa até 2004, passando à moderada em 2005 (Tabela 5). Entre as oito microrregiões (CR8) a concentração é classificada como baixa após 2005, antes disso, era ausente.

Tabela 5 - Razão de Concentração, Herfindahl-Hirschman, total de rebanhos de suínos de Minas Gerais, 1990-2012

\begin{tabular}{c|c|c|c|c|c|c|c|c|c}
\hline Ano & CR4 & CR8 & HHI & Total & Ano & CR4 & CR8 & HHI & Total \\
\hline 1990 & $14 \%$ & $25 \%$ & 199 & 3.295 .930 & 2002 & $31 \%$ & $42 \%$ & 415 & 3.310 .240 \\
\hline 1991 & $14 \%$ & $25 \%$ & 196 & 3.290 .065 & 2003 & $32 \%$ & $42 \%$ & 422 & 3.371 .624 \\
\hline 1992 & $17 \%$ & $28 \%$ & 227 & 3.363 .767 & 2004 & $33 \%$ & $44 \%$ & 456 & 3.535 .101 \\
\hline 1993 & $17 \%$ & $28 \%$ & 220 & 3.328 .746 & 2005 & $36 \%$ & $47 \%$ & 558 & 3.792 .958 \\
\hline 1994 & $18 \%$ & $29 \%$ & 236 & 3.390 .683 & 2006 & $37 \%$ & $48 \%$ & 567 & 3.870 .593 \\
\hline 1995 & $18 \%$ & $28 \%$ & 235 & 3.367 .748 & 2007 & $40 \%$ & $51 \%$ & 648 & 4.199 .138 \\
\hline
\end{tabular}


Concentração espacial dos rebanhos de suínos no Brasil entre 1990 e 2012 Laércio Juarez Melz

Tiane Alves Rocha Gastardelo

Pascoal José Marion Filho

\begin{tabular}{c|c|c|c|c|c|c|c|c|c|c}
\hline & \multicolumn{1}{l}{1996} & $21 \%$ & $32 \%$ & 270 & 2.533 .484 & 2008 & $40 \%$ & $52 \%$ & 673 & 4.322 .910 \\
\hline 1997 & $21 \%$ & $33 \%$ & 266 & 2.611 .301 & 2009 & $42 \%$ & $53 \%$ & 699 & 4.639 .825 \\
\hline 1998 & $21 \%$ & $33 \%$ & 279 & 2.655 .566 & 2010 & $45 \%$ & $56 \%$ & 889 & 5.021 .973 \\
\hline 1999 & $30 \%$ & $41 \%$ & 392 & 3.011 .407 & 2011 & $44 \%$ & $56 \%$ & 800 & 5.014 .334 \\
\hline 2000 & $30 \%$ & $40 \%$ & 390 & 3.142 .220 & 2012 & $46 \%$ & $57 \%$ & 825 & 5.157 .142 \\
\hline 2001 & $33 \%$ & $44 \%$ & 453 & 3.358 .696 & & & & & \\
\hline
\end{tabular}

Fonte : Elaborado pelos autores com dados do IBGE (2014).

A microrregião mineira que mais contribuiu para o aumento dos níveis de concentração foi Uberlândia que, em 2004, aumentou consideravelmente seu rebanho. A microrregião de Ponte Nova, que era a principal produtora de suínos até 2004, manteve crescimento regular do rebanho, porém, em 2012, tinha somente $62 \%$ do número de animais que a região de Uberlândia.

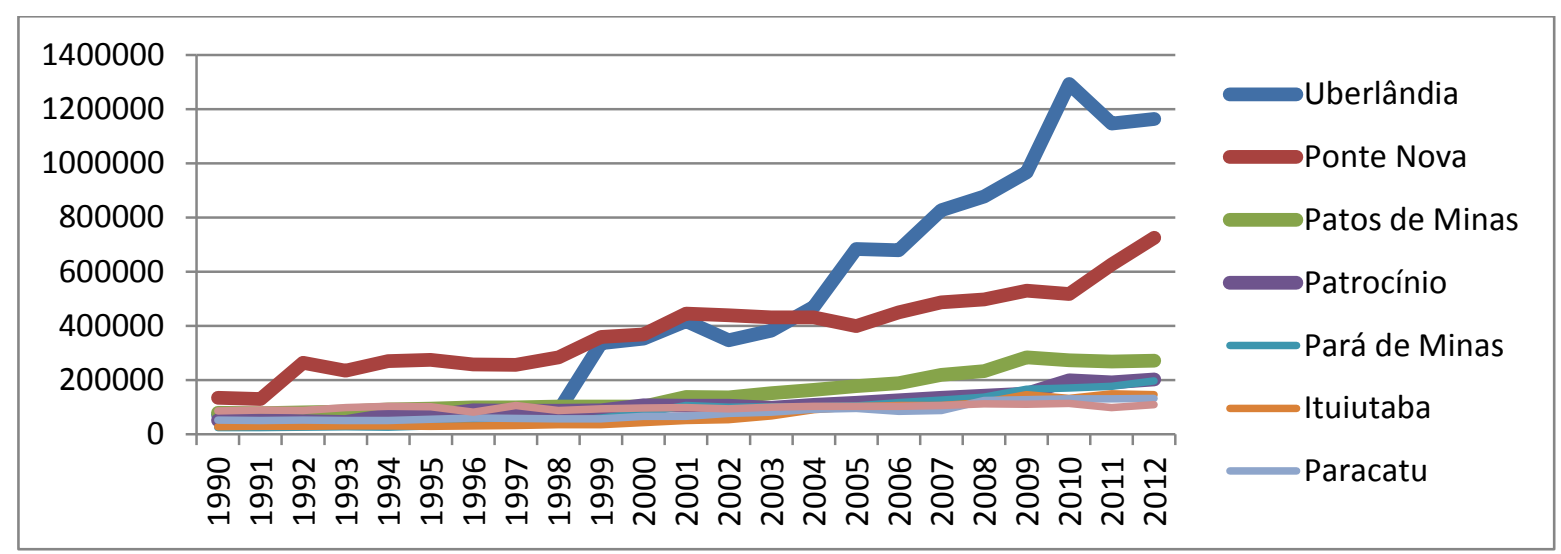

Figura 4 - Rebanho de suínos nas microrregiões de Minas Gerais, em cabeças, 1990-2012 Fonte : Elaborado pelos autores com dados do IBGE (2014).

Na Tabela 6 é observa-se que, em São Paulo, o nível de concentração entre as microrregiões vem se mantendo extremamente baixo em todo o período analisado (ausência de concentração). O CR4 indica que as quatro maiores microrregiões em número de suínos tem concentrado 27\%, em média, desde 1990. O CR8 médio de 42\% entre 1990 e 2012 também indica ausência de concentração. O HHI indica que houve pequeno aumento da concentração nos anos analisados, porém com ausência de concentração. O total do rebanho paulista de suínos, contudo, vem diminuindo. Entre 1990 e 2012 a redução foi de $23 \%$. Isso significa que um aumento da concentração ocorreu pela redução dos rebanhos em microrregiões como São José do Rio Preto (redução de 92 mil cabeças), Jaboticabal (- 51 mil cabeças) e Adamantina (- 41,5 mil cabeças), entre outras. Somente 12 das 52 microrregiões do estado tiveram aumento dos rebanhos. 
Concentração espacial dos rebanhos de suínos no Brasil entre 1990 e 2012 Laércio Juarez Melz

Tiane Alves Rocha Gastardelo

Pascoal José Marion Filho

Tabela 6 - Razão de Concentração, Herfindahl-Hirschman, total de rebanhos de suínos de São Paulo, 1990-2012

\begin{tabular}{c|c|c|c|c|c|c|c|c|c}
\hline Ano & CR4 & CR8 & HHI & Total & Ano & CR4 & CR8 & HHI & Total \\
\hline 1990 & $21 \%$ & $36 \%$ & 271 & 2.027 .007 & 2002 & $30 \%$ & $46 \%$ & 382 & 1.845 .427 \\
\hline 1991 & $23 \%$ & $37 \%$ & 281 & 2.081 .405 & 2003 & $27 \%$ & $44 \%$ & 354 & 1.709 .256 \\
\hline 1992 & $23 \%$ & $36 \%$ & 281 & 2.035 .986 & 2004 & $28 \%$ & $44 \%$ & 362 & 1.698 .619 \\
\hline 1993 & $23 \%$ & $36 \%$ & 281 & 2.014 .936 & 2005 & $28 \%$ & $44 \%$ & 372 & 1.706 .862 \\
\hline 1994 & $25 \%$ & $38 \%$ & 307 & 2.098 .958 & 2006 & $29 \%$ & $44 \%$ & 377 & 1.727 .955 \\
\hline 1995 & $25 \%$ & $39 \%$ & 312 & 2.142 .888 & 2007 & $29 \%$ & $44 \%$ & 378 & 1.724 .228 \\
\hline 1996 & $25 \%$ & $39 \%$ & 333 & 1.849 .226 & 2008 & $28 \%$ & $44 \%$ & 368 & 1.691 .356 \\
\hline 1997 & $27 \%$ & $41 \%$ & 347 & 1.834 .568 & 2009 & $26 \%$ & $41 \%$ & 360 & 1.639 .247 \\
\hline 1998 & $30 \%$ & $45 \%$ & 385 & 1.934 .269 & 2010 & $27 \%$ & $42 \%$ & 365 & 1.693 .632 \\
\hline 1999 & $30 \%$ & $45 \%$ & 383 & 1.913 .372 & 2011 & $26 \%$ & $41 \%$ & 353 & 1.599 .515 \\
\hline 2000 & $30 \%$ & $46 \%$ & 382 & 1.902 .275 & 2012 & $27 \%$ & $44 \%$ & 385 & 1.557 .481 \\
\hline 2001 & $29 \%$ & $44 \%$ & 372 & 1.903 .813 & & & & & \\
\hline
\end{tabular}

Fonte : Elaborado pelos autores com dados do IBGE (2014).

Na Figura 5 é possível observar a queda da produção de suínos entre as oito maiores microrregiões, a partir de 2008. As microrregiões de São Paulo que tem se destacado são: Sorocaba, Ourinhos, Avaré e Bauru, que permaneceram entre as quatro maiores produtoras de suínos em 2012. Porém, é preciso ressaltar que existe grande instabilidade no número de cabeças de suínos ao longo dos anos. Sorocaba, por exemplo, teve um brusco aumento de rebanhos em 1994 e Avaré, em 1998.

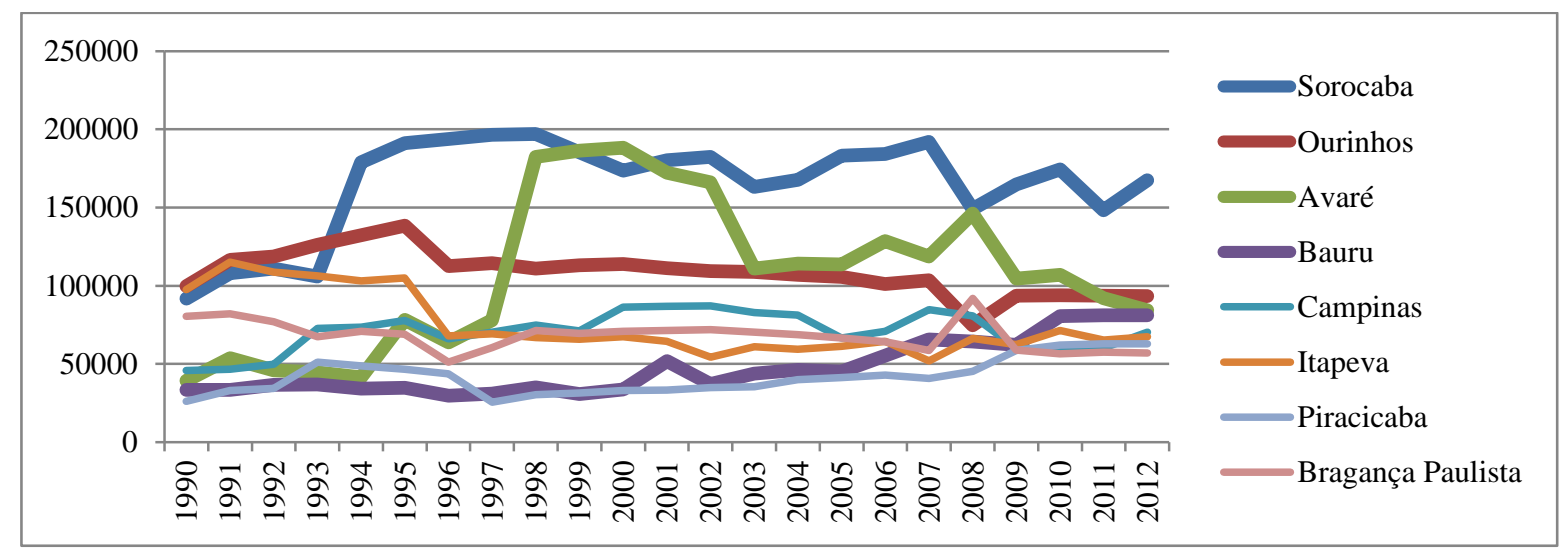

Figura 5 - Rebanho de suínos nas microrregiões de São Paulo, em cabeças, 1990-2012 Fonte : Elaborado pelos autores com dados do IBGE (2014).

O estado de Goiás é composto por 18 microrregiões. Assim, para uma distribuição igualitária dos rebanhos entre as microrregiões (1/18), o nível de concentração para cada microrregião seria de $5,6 \%$. Para as quatro microrregiões com maiores rebanhos seria de $22 \%$ e para as oito maiores, 44\%. A Tabela 7 mostra que, em Goiás, em 1990, o nível de concentração evidenciado pelo CR4 e CR8 era baixo. A partir de 2002, o nível de concentração espacial passou a ser moderado entre os quatro maiores produtores. Em 2012 a concentração pode ser classificada como alta entre as quatro microrregiões mais relevantes. $\mathrm{O}$ 
Concentração espacial dos rebanhos de suínos no Brasil entre 1990 e 2012

Laércio Juarez Melz

Tiane Alves Rocha Gastardelo

Pascoal José Marion Filho

CR8 apontou concentração moderada a partir de 2001, mantendo-se neste patamar até 2012, porém, com tendência de aumento.

O HHI confirma a tendência de aumento de concentração. Pela interpretação de USDJ e FTC (2010), entre 1990 e 2002 a concentração inexistia, entre 2003 e 2011 passou a ser moderada e, em 2012, a produção passou a ser altamente concentrada no estado.

Tabela 7 - Razão de Concentração, Herfindahl-Hirschman, total de rebanhos de suínos de Goiás, 1990-2012

\begin{tabular}{c|c|c|c|c|c|c|c|c|c}
\hline Ano & CR4 & CR8 & HHI & Total & Ano & CR4 & CR8 & HHI & Total \\
\hline 1990 & $38 \%$ & $67 \%$ & 691 & 1.876 .735 & 2002 & $52 \%$ & $74 \%$ & 1.315 & 1.360 .573 \\
\hline 1991 & $38 \%$ & $67 \%$ & 692 & 1.933 .455 & 2003 & $57 \%$ & $76 \%$ & 1.687 & 1.499 .050 \\
\hline 1992 & $39 \%$ & $67 \%$ & 693 & 1.887 .139 & 2004 & $56 \%$ & $76 \%$ & 1.585 & 1.493 .837 \\
\hline 1993 & $38 \%$ & $67 \%$ & 697 & 1.904 .893 & 2005 & $55 \%$ & $76 \%$ & 1.524 & 1.499 .138 \\
\hline 1994 & $37 \%$ & $67 \%$ & 692 & 1.896 .470 & 2006 & $56 \%$ & $76 \%$ & 1.522 & 1.516 .285 \\
\hline 1995 & $36 \%$ & $66 \%$ & 682 & 1.869 .052 & 2007 & $56 \%$ & $76 \%$ & 1.517 & 1.537 .430 \\
\hline 1996 & $38 \%$ & $66 \%$ & 693 & 1.065 .789 & 2008 & $59 \%$ & $78 \%$ & 1.711 & 1.592 .760 \\
\hline 1997 & $36 \%$ & $66 \%$ & 680 & 1.027 .963 & 2009 & $64 \%$ & $80 \%$ & 2.308 & 1.929 .062 \\
\hline 1998 & $37 \%$ & $65 \%$ & 682 & 1.034 .767 & 2010 & $65 \%$ & $81 \%$ & 2.451 & 2.046 .727 \\
\hline 1999 & $41 \%$ & $67 \%$ & 773 & 1.113 .518 & 2011 & $65 \%$ & $80 \%$ & 2.445 & 2.049 .376 \\
\hline 2000 & $44 \%$ & $69 \%$ & 895 & 1.174 .360 & 2012 & $66 \%$ & $81 \%$ & 2.610 & 2.016 .444 \\
\hline 2001 & $47 \%$ & $71 \%$ & 919 & 1.231 .251 & & & & & \\
\hline
\end{tabular}

Fonte : Elaborado pelos autores com dados do IBGE (2014).

Na Figura 6 é possível verificar que, desde 1999, a microrregião Sudoeste de Goiás rapidamente se destacou das demais e, em 2012, é a principal produtora de suínos do estado. Somente nesta microrregião houve um aumento de 828 mil cabeças de suínos entre 1990 e 2012, concentrando 49\% dos rebanhos do estado. Várias microrregiões reduziram seus rebanhos no período. Destacam-se as microrregiões de Porangatu e Ceres que, juntas, reduziram seus rebanhos em 250 mil cabeças no mesmo período.

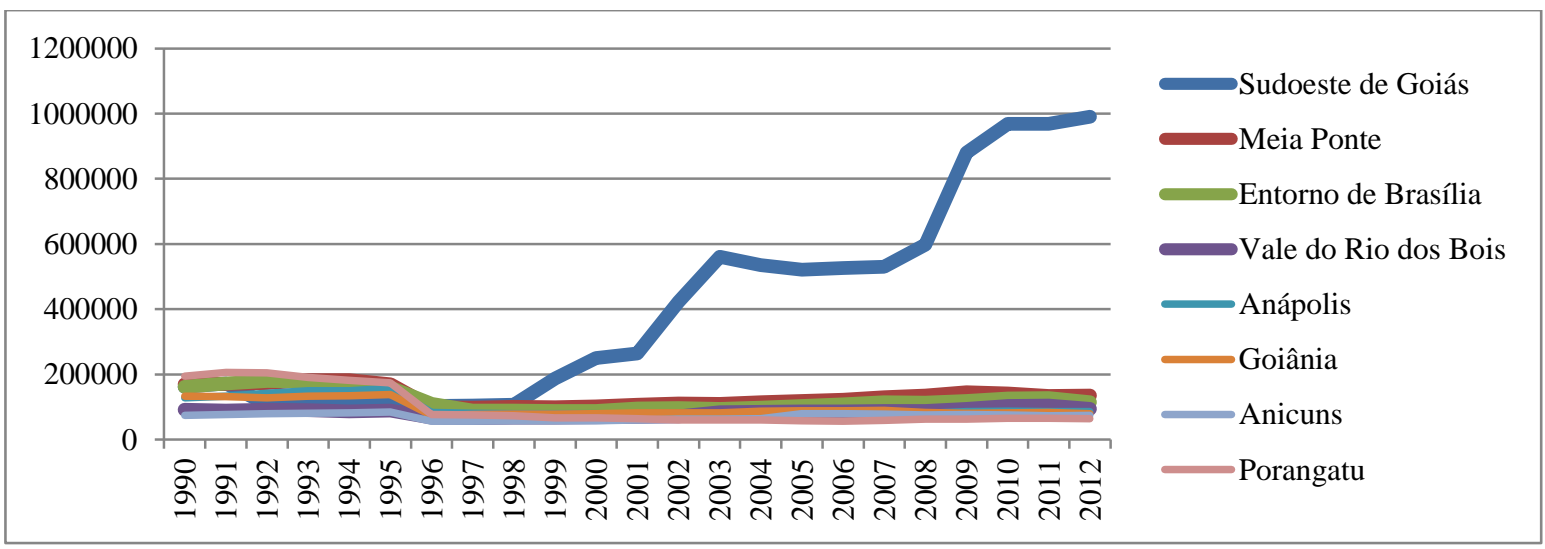

Figura 6 - Rebanho de suínos nas microrregiões de Goiás, em cabeças, 1990-2012

Fonte : Elaborado pelos autores com dados do IBGE (2014). 
Concentração espacial dos rebanhos de suínos no Brasil entre 1990 e 2012

Laércio Juarez Melz

Tiane Alves Rocha Gastardelo

Pascoal José Marion Filho

Em Mato Grosso pode-se afirmar que o nível de concentração está muito além de uma distribuição igualitária. Com 22 microrregiões, o estado teria uma distribuição igualitária se cada uma tivesse $4,5 \%$ do total do rebanho suíno do estado. Assim, as quatro maiores (CR4) teriam $18 \%$ e as oito (CR8) teriam 36\%. Pela classificação de Medeiros e Ostroki (2006), o índice CR4, em Mato Grosso, passou por um período de ausência de concentração (1995) e períodos de concentração baixa, entre 1990 e 2003 (exceto 1995). Entre 2004 e 2008 a concentração foi moderada. Após 2009 a concentração passou a ser alta entre as quatro microrregiões com maior rebanho suíno (Tabela 8). Entre as oito maiores (CR8) o nível de concentração baixa foi observado até 2003 , seguido de um período de concentração moderada de 2004 até 2012.

Pelo HHI é possível confirmar que houve grande aumento na concentração da produção de suínos no estado. Por este índice, até 2007 inexistia concentração, quadro que mudou, quando em 2008 a concentração passou a ser moderada e, em 2012, a produção de suínos no estado torna-se altamente concentrada.

Tabela 8 - Razão de Concentração, Herfindahl-Hirschman, total de rebanhos de suínos de Mato Grosso, 1990-2012

\begin{tabular}{c|c|c|c|c|c|c|c|c|c}
\hline Ano & CR4 & CR8 & HHI & Total & Ano & CR4 & CR8 & HHI & Total \\
\hline 1990 & $43 \%$ & $66 \%$ & 729 & 1.034 .107 & 2002 & $47 \%$ & $68 \%$ & 805 & 1.034 .608 \\
\hline 1991 & $40 \%$ & $65 \%$ & 681 & 1.039 .732 & 2003 & $49 \%$ & $69 \%$ & 822 & 1.114 .592 \\
\hline 1992 & $37 \%$ & $59 \%$ & 631 & 872.351 & 2004 & $52 \%$ & $72 \%$ & 970 & 1.315 .443 \\
\hline 1993 & $36 \%$ & $59 \%$ & 617 & 893.333 & 2005 & $53 \%$ & $72 \%$ & 998 & 1.359 .824 \\
\hline 1994 & $36 \%$ & $60 \%$ & 616 & 947.629 & 2006 & $54 \%$ & $74 \%$ & 1.091 & 1.439 .626 \\
\hline 1995 & $35 \%$ & $60 \%$ & 603 & 990.802 & 2007 & $56 \%$ & $73 \%$ & 1.238 & 1.392 .424 \\
\hline 1996 & $39 \%$ & $63 \%$ & 635 & 689.514 & 2008 & $61 \%$ & $77 \%$ & 1.546 & 1.620 .061 \\
\hline 1997 & $40 \%$ & $63 \%$ & 651 & 724.651 & 2009 & $65 \%$ & $80 \%$ & 2.065 & 1.864 .808 \\
\hline 1998 & $40 \%$ & $63 \%$ & 653 & 759.928 & 2010 & $70 \%$ & $82 \%$ & 2.351 & 2.109 .979 \\
\hline 1999 & $41 \%$ & $64 \%$ & 655 & 771.157 & 2011 & $68 \%$ & $82 \%$ & 2.229 & 1.954 .128 \\
\hline 2000 & $43 \%$ & $64 \%$ & 712 & 834.084 & 2012 & $70 \%$ & $82 \%$ & 2.552 & 1.789 .390 \\
\hline 2001 & $42 \%$ & $65 \%$ & 714 & 934.889 & & & & & \\
\hline
\end{tabular}

Fonte : Elaborado pelos autores com dados do IBGE (2014).

A Figura 7 mostra que, em Mato Grosso, uma das microrregiões apresentou crescimento acelerado nos rebanhos, assim como aconteceu no Paraná, Goiás e Minas Gerais,. Foi a região do Alto Teles Pires, cujo rebanho teve aumento de $3450 \%$ no número de animais, entre 1990 e 2012, chegando a primeira posição no ranking em 1996. O rebanho de 861 mil cabeças de suínos correspondeu a 48\% do rebanho do estado, em 2012. A segunda microrregião com maior rebanho, Sinop, possuia apenas $10 \%$ do rebanho neste mesmo ano. Esta microrregião somente passou para o grupo CR4 em 2007. As microrregiões de Primavera do Leste e Parecis participaram, cada uma, com 6\% dos rebanhos de Mato Grosso em 2012. 
Concentração espacial dos rebanhos de suínos no Brasil entre 1990 e 2012

Laércio Juarez Melz

Tiane Alves Rocha Gastardelo

Pascoal José Marion Filho

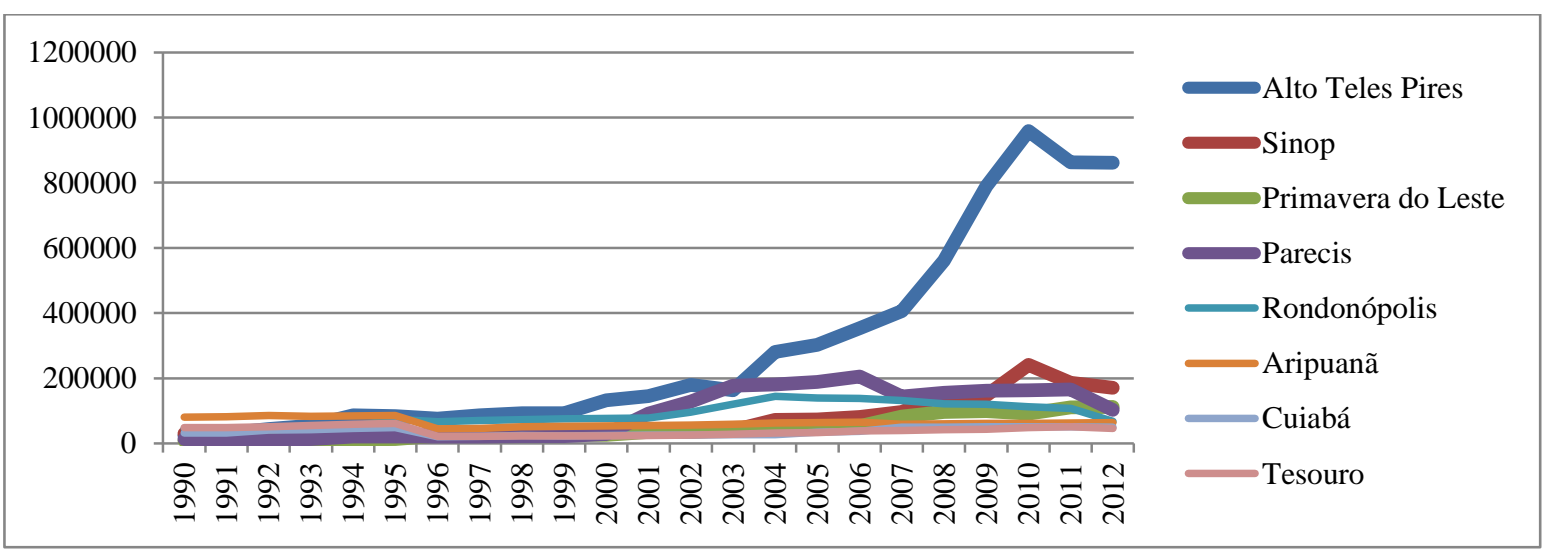

Figura 7- Rebanho de suínos nas microrregiões de Mato Grosso, em cabeças, 1990-2012 Fonte : Elaborado pelos autores com dados do IBGE (2014).

A Bahia é composta por 32 microrregiões. Para um distribuição igualitária dos rebanhos, cada microrregião teria participação de 3,13\%, sendo esperado CR4=13\% e $\mathrm{CR} 8=25 \%$. O índice CR4 demonstra que o nível de concentração um pouco superior à distribuição igualitária, 30\%, denotando ausência de concentração na maioria dos anos entre 1990 e 2012. Entre as oito microrregiões com maiores rebanhos a concentração pode ser classificada como baixa, não tendo ultapassado os 53\%. O HHI aponta pequeno aumento nos níveis de concentração, considerando todas microrregiões da Bahia, contudo pela classificação adotada pelo USDJ e FTC (2010) a concentração inexiste no estado, confirmando os resultados do CR.

Tabela 9 - Razão de Concentração, Herfindahl-Hirschman, total de rebanhos de suínos da Bahia, 1990-2012

\begin{tabular}{c|c|c|c|c|c|c|c|c|c}
\hline Ano & CR4 & CR8 & HHI & Total & Ano & CR4 & CR8 & HHI & Total \\
\hline 1990 & $30 \%$ & $50 \%$ & 462 & 2.351 .126 & 2002 & $35 \%$ & $53 \%$ & 512 & 1.981 .284 \\
\hline 1991 & $30 \%$ & $51 \%$ & 469 & 2.446 .931 & 2003 & $35 \%$ & $53 \%$ & 515 & 1.966 .482 \\
\hline 1992 & $32 \%$ & $53 \%$ & 487 & 2.519 .515 & 2004 & $35 \%$ & $53 \%$ & 526 & 1.973 .748 \\
\hline 1993 & $33 \%$ & $53 \%$ & 487 & 2.270 .577 & 2005 & $34 \%$ & $52 \%$ & 510 & 1.993 .461 \\
\hline 1994 & $33 \%$ & $53 \%$ & 489 & 2.334 .344 & 2006 & $34 \%$ & $52 \%$ & 514 & 2.006 .734 \\
\hline 1995 & $34 \%$ & $54 \%$ & 504 & 2.377 .801 & 2007 & $34 \%$ & $51 \%$ & 516 & 1.904 .699 \\
\hline 1996 & $29 \%$ & $48 \%$ & 444 & 1.804 .261 & 2008 & $33 \%$ & $50 \%$ & 518 & 1.835 .017 \\
\hline 1997 & $30 \%$ & $49 \%$ & 449 & 1.832 .058 & 2009 & $34 \%$ & $51 \%$ & 548 & 1.753 .475 \\
\hline 1998 & $30 \%$ & $49 \%$ & 461 & 1.837 .378 & 2010 & $35 \%$ & $51 \%$ & 562 & 1.768 .305 \\
\hline 1999 & $31 \%$ & $51 \%$ & 476 & 1.970 .778 & 2011 & $34 \%$ & $51 \%$ & 536 & 1.620 .697 \\
\hline 2000 & $33 \%$ & $52 \%$ & 495 & 2.027 .787 & 2012 & $35 \%$ & $50 \%$ & 523 & 1.513 .425 \\
\hline 2001 & $33 \%$ & $53 \%$ & 500 & 2.052 .603 & & & & & \\
\hline
\end{tabular}

Fonte : Elaborado pelos autores com dados do IBGE (2014).

Com relação ao número total de cabeças de suínos na Bahia, houve redução de $36 \%$ entre 1990 e 2012. Pode-se verificar, na Figura 8, que a microrregião de Feira de Santana, 
Concentração espacial dos rebanhos de suínos no Brasil entre 1990 e 2012

Laércio Juarez Melz

Tiane Alves Rocha Gastardelo

Pascoal José Marion Filho

diferente das demais, aumentou seus rebanhos em $28 \%$. As demais microrregiões que fazem parte do grupo das 4 maiores tiveram redução dos seus rebanhos.

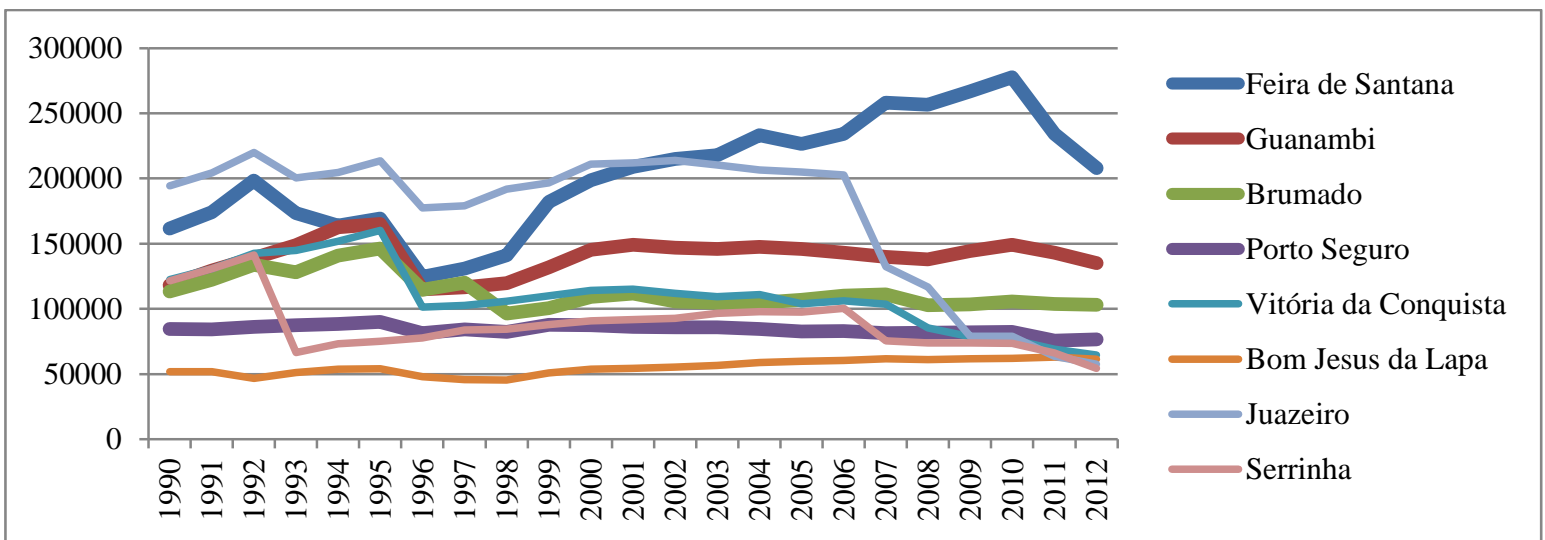

Figura 8 - Rebanho de suínos nas microrregiões da Bahia, em cabeças, 1990-2012 Fonte : Elaborado pelos autores com dados do IBGE (2014).

A comparação entre as Razões de Concentração (CR) e o Índice de HerfindahlHirschman (HHI) demonstra que houve aumento dos níveis de concentração na maior parte dos estados brasileiros entre 1990 e 2012.

\subsection{Evolução da concentração entre as microrregiões dos estados}

A Figura 9 mostra a evolução do índice CR4 das microrregiões entre os oito estados com maior participação no rebanho suíno nacional, entre 1990 e 2012. As linhas pontilhadas representam os limites estabelecidos por Medeiros e Ostroski (2006) para classificação dos níveis de concentração em Ausência (até 35\%), Baixa (até 50\%), Moderada (até 65\%), Alta (até $75 \%$ ) e Altíssima (maior que 75\%). As linhas sólidas representam os oito estados com maiores rebanhos do Brasil. Os índices são mais altos em Santa Catarina, Goiás e Mato Grosso. 


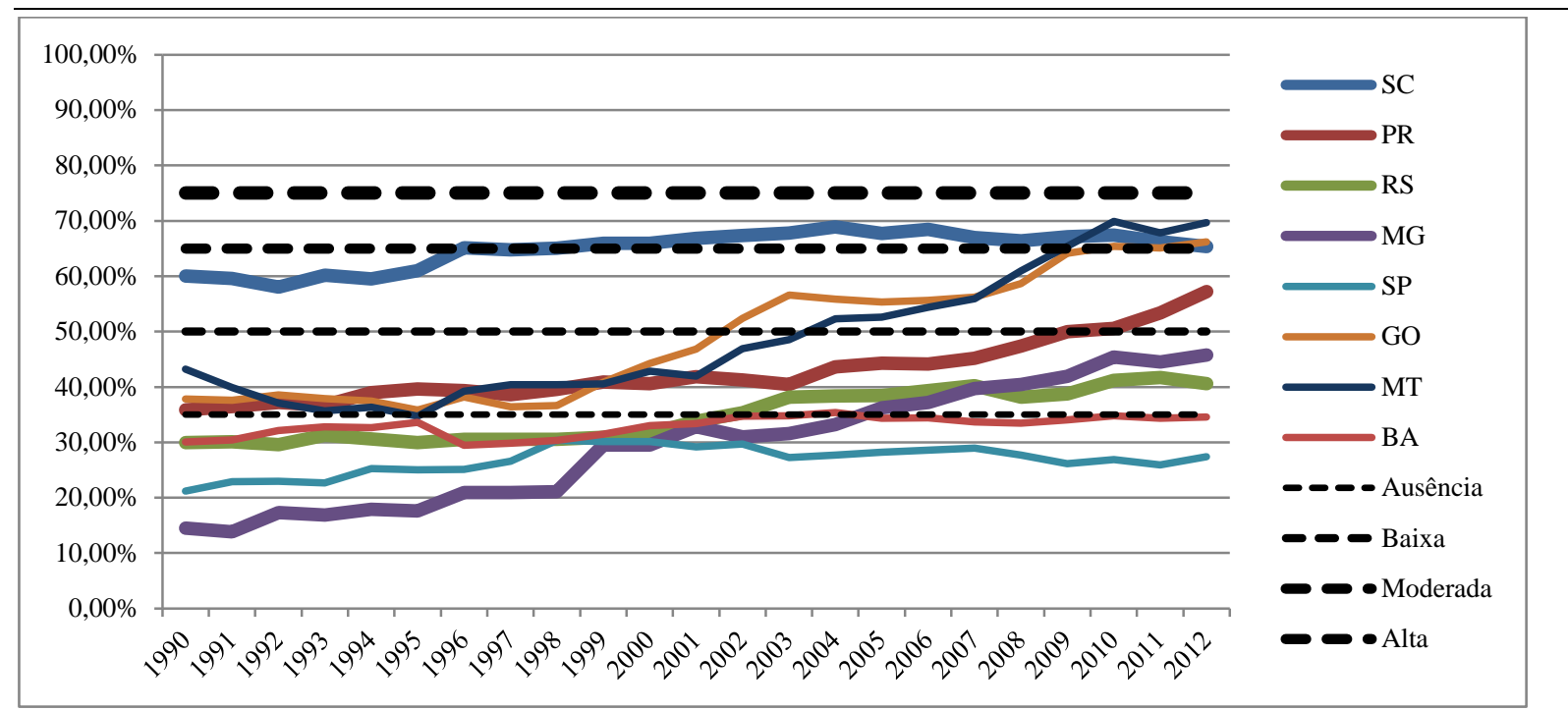

FiFigura 9 - Evolução da Razão de Concentração (CR4) das microrregiões entre os oito maiores estados produtores de suínos do Brasil, 1990-2012, em percentual

Fonte : Elaborado pelos autores com dados do IBGE (2014).

Santa Catarina, desde o início da série apresenta níveis altos de concentração em quatro microrregiões desde 1996. A Associação Catarinense de Criadores de Suínos (ACCS, 2012), afirma que a suinocultura, no Oeste, região de maior concentração foi trazida ao estado por agricultores do Rio Grande do Sul e impulsionada pela abundância do milho, ao parque industrial pioneiro e sua adaptação à pequena propriedade. Havia, em 2011, quatro abatedouros de grande capacidade (MS1) pertencentes à BRF (Sadia e Perdigão) e dois pertencentes à Cooperativa Central do Oeste Catarinense (Aurora). Também havia instalados abatedores de menores capacidades, MS3 (3), MS4(7) e MS5(3) (MAPA, 2011). A Figura 10A mostra que desde 1990, os rebanhos no Oeste do estado já eram destaque no cenário nacional, com mais de 200 mil cabeças de suínos. Entende-se que os níveis de concentração são característicos do estado e, provavelmente, não se alterarão ao longo dos anos, já que grande parte dos abatedouros e processadores de carnes suínas localizam-se na região chamada de 'Grande Oeste'.

Goiás e Mato Grosso foram os estados que destacaram-se em aumento do nível de concentração. O primeiro começou um acelerado ritmo de concentração em quatro microrregioes no ano de 1999. Lopes (1997) apontava aumento de concentração da produção de suinos no Sul de Goiás, justificando-a pela grande produção de grãos, milho e soja, na região. O autor afirmou, também, que o estado teria grande potencial para suinocultura, por esse motivo. O aumento da concentração em torno da região Sul, essencialemente na microrregião do Sudoeste de Goiás, ocorreu a patir de 1999 e justifica-se também pela 
Concentração espacial dos rebanhos de suínos no Brasil entre 1990 e 2012

Laércio Juarez Melz

Tiane Alves Rocha Gastardelo

Pascoal José Marion Filho

instalação, no ano de 2000, do único frigorifico de suínos do estado inspecionado pelo Sistem de Inspeção Federal (SIF) classificado como grande porte (MS1) (MAPA, 2011). O estabelecimento, pertencente à BRF, foi instalado no município de Rio Verde, microrregião Sudoeste de Goiás.

Mato Grosso iniciou o processo de concentração em 2001. Saraiva (2012) aponta algumas características que diferenciam o estado em termos de competitividade, entre elas, a grande produção de grãos, os ganhos de escala de produção, o fato de ser área livre de febre aftosa e peste suína clássica, além da existência do programa do governo estadual 'Granja de Qualidade'. O autor associa maior Índice de Desempenho Competitivo aos municípios com maiores rebanhos suínos, Lucas do Rio Verde, Nova Mutum, Sorriso, Santa Rita do Trivelato, Tapurah, na microrregião do Alto Teles Pires, e Rondonópolis, na microrregião de mesmo nome. No estado, em 2011, estavam instalados quatro estabelecimentos inspecionados pelo Serviço de Inspeção Federal (SIF), nenhum de grande porte, apenas um classificado como MS2, um MS4 e dois MS5 (MAPA, 2011). Também havia, no mesmo ano, dois frigorificos de suínos e quatro mistos (bovino e suíno) registrados no Serviço de Inspeção Sanitária Estadual (INDEA/MT, 2012).

A Figura 10 ilustra o quadro de concentração entre as microrregiões do Brasil. Pode-se ver claramente que a produção de suínos tem migrado para o Oeste dos estados da Região Sul e para algumas microrregiões da Região Centro-Oeste.

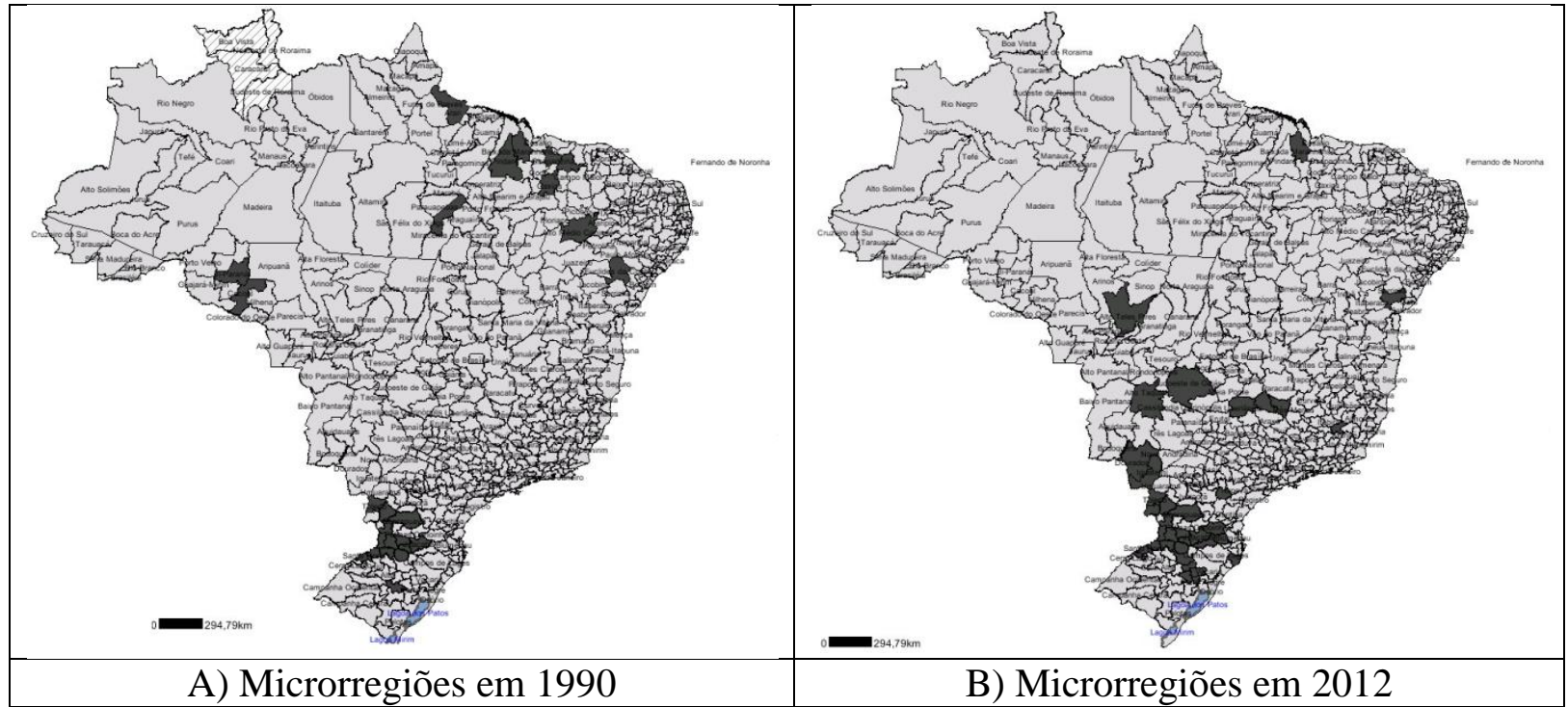

Figura 10 - Mapa das microrregiões com mais de 200 mil cabeças de suínos em 1990 e 2012 Fonte : IBGE (2014). 
A semelhança entre as microrregiões, apontada por ACCS (2012), Lopes (1997) e Saraiva (2012), é a abundancia de grãos, principalmente o milho, que é o principal insumo para a produção de suínos. Weydmann (2004) afirma que a concentração da produção de suínos é fruto da modernização da indústria que passa a depender de produtores com maiores escalas de produção, disponbilidade de terras e de mão-de-obra, excluíndo os suinocultores menos competitivos.

\section{CONSIDERAÇÕES FINAIS}

Considerando que a inserção de novos players em um mercado reduz os níveis de concentração, o objetivo deste artigo foi verificar se houve redução ou aumento da concentração espacial da produção de suínos no Brasil no contexto dos estados e das microrregiões. Como objetivo secundário, pretende-se apresentar as mudanças entre os principais locais de produção entre os anos de 1990 e 2012.

Verificou-se que houve aumento da concentração entre quatro estados, Santa Catarina, Rio Grande do Sul, Paraná e Minas Gerais, passando de 41\% para 63\% entre 1990 e 2012. Além destes, São Paulo, Goiás, Mato Grosso e Bahia integram o grupo dos oito maiores produtores, em 2012. Exceto por São Paulo, todos os estados listados entre os oito mariores produtores tiveram aumentos em seus níveis de concentração. Destacam-se Santa Catarina, Goías e Mato Grosso. Em todos os casos o Índice de Herfindahl-Hirschman confirma as tendências de concentração.

Em Santa Catarina estão os maiores índices de concentração entre as microrregiões no país em todos os períodos analisados. Goiás e Mato Grosso apresentaram grande aumento no nível de concentração. Sendo que MT apresentou concentração maior que SC em 2012. O principal fator apontado pela literatura como responsável pela concentração da produção de suínos foi a abundância de milho nas microrregiões.

Entre as limitações impostas, está o fato de que os índices utilizados (CR e HHI), são amplamente aplicados no âmbito das firmas, aqui adaptados à produção regional. Contudo, a comparação entre diferentes períodos permite verificar a evolução destes índices, que foi o objetivo proposto. Sugere-se outros métodos e indicadores sejam utilizados para corroborar ou contestar os resultados aqui apresentados para melhor conhecimento da produção e desenvolvimento da ciência. 


\section{REFERÊNCIAS}

ACCS. Associação Catarinense de Criadores de Suínos. Relatórios anuais, 2014. Disponivel em: 〈http://www.accs.org.br/arquivos_internos/index.php?abrir=relatorios_anuais >. Acesso em: 12 mar. 2014.

IBGE. Instituto Brasileiro de Geografia e Estatística. Sistema IBGE de Recuperação Automática de dados - SIDRA, 2014. Disponivel em: <http://www.sidra.ibge.gov.br/>. Acesso em: 2 fev. 2014.

INDEA/MT. Instituto de Defesa Agropecuária do Estado de Mato Grosso. Estabelecimentos Registrados no SISE, 2012. Disponivel em:

$<$ http://www.indea.mt.gov.br/html/internas.php?tabela=paginas\&codigoPagina=32>. Acesso em: 17 mar. 2013.

IPARDES; IBQP; GEPAI. Análise da competitividade da cadeia agroindustrial de carne suína no Estado do Paraná. Curitiba: IPARDES, 2002.

LOPES, R. L. Suinocultura no estado de Goiás: uma aplicação do modelo de localização. [Dissertação] Mestrado em Economia Aplicada. ESALQ/USP. Piracicaba-SP, p. 208. 1997.

MAPA. Ministério da Agricultura, Pecuária e Abastecimento. Relação de Estabelecimentos, 2011. Disponivel em:

<http://sigsif.agricultura.gov.br/sigsif_cons/!ap_estabelec_nacional_rep>. Acesso em: 12 mar. 2014.

MEDEIROS, N. H.; OSTROSKI, D. A. Competitividade e concentração de mercado: uma análise da avicultura nas mesorregiões oeste e sudoeste paranaense. XLIV Congresso da SOBER, Fortaleza, 2006.

MELZ, L. J.; GASPARINI, L. V. L.; SOUZA FILHO, H. M. Análise da concentração espacial dos alojamentos de frangos no Brasil. In: 47 Congresso da Sociedade Brasileira de Economia, Administração e Sociologia Rural (SOBER), Porto Alegre, 2009.

NATIONAL PORK BOARD. Pork History and Lore: History of the Pig and the U.S. Pork Industry, 2014. Disponivel em:

<http://www.porkandhealth.org/PorkPreparation/69/PorkHistoryandLore.aspx\#.U2ozDPldWS o>. Acesso em: 07 maio 2014.

NELSON, S. M. Ancestors for the pigs: pigs in prehistory. Pennsylvania: Penn Press, 1998.

RESENDE, M.; BOFF, H. Concentração industrial. In: KUPFER, D.; HASENCLEVER, L. Economia industrial: fundamentos teóricos e práticas no Brasil. Rio de Janeiro: Elsevier, 2002. Cap. 4, p. 73-108.

RHOADES, S. A. Market share as a source of market power: Implications and some evidence. Journal of Economics and Business, v.37, n. 4, dec. 1985. p.343-363.

SANTOS, R. C. et al. Perdas econômicas decorrentes do transporte de suínos em Mato Grosso do Sul: estudo de caso. Enciclopédia Biosfera, Centro Científico Conhecer, Goiânia, v.9, n. 16, 2013. p.1682-1697. 
SARAIVA, M. B. Índice de desempenho competitivo da suinocultura das principais regiões produtoras de Mato Grosso: análise dos fatores determinantes. [Dissertação] Mestrado em Agronegócio e Desenvolvimento Regional. UFMT. Cuiabá-MT, p. 90. 2011.

USDJ; FTC. U.S. Department of Justice; Federal Trade Commission. Horizontal Mergers Guidelines, 2010. Disponivel em: <http://www.ftc.gov/sites/default/files/attachments/mergerreview/100819hmg.pdf >. Acesso em: 26 mar. 2013.

VIGNE, J. et al. Pre-Neolithic wild boar management and introduction to Cyprus more than 11,400 years ago. Proceedings of the National Academy of Sciences of the United States of America, New Haven, v. 106, n. 38, p. 16135-16138, Set 2009.

WEYDMANN, C. L. O padrão concorrencial na agroindústria suína e as estratégias ambientais. In: GUIVANT, J. S.; MIRANDA, C. R. D. Desafios para o desenvolvimento sustentável da suinocultura: uma abordagem multidisciplinar. Chapecó: Argos, 2004. p. $332 \mathrm{p}$. 